IJADR

International Journal of Alcohol and Drug Research

The Official Journal of the Kettil Bruun Society for Social and Epidemiological Research on Alcohol

doi: 10.7895/ijadr.v4i2.207

IJADR, 2015, 4(2), 97 - 99

ISSN: 1925-7066

\title{
Commentary: The land of insurmountable opportunities
}

\author{
Robert W. Denniston
}

Recently retired after 36 years of federal service, including stints at the National Institute on Alcohol Abuse and Alcoholism, the Substance Abuse and Mental Health Services Administration, and the Office of National Drug Control Policy. He has been a long-time champion for prevention policies and programs and has actively supported the Alcohol Policy Conferences. He received career recognition awards from the American Public Health Association and the National Prevention Network

\begin{abstract}
Much is known about how to change alcohol policy to reduce harm, but despite the evidence little action has been taken at the national level in the United States. Government officials have shown little interest in putting prevention research results to work. The influence of the alcohol industry on policy-makers combined with free market ideology has thwarted change despite the efforts of advocacy groups working to reduce harm. The role of the alcohol industry at the national and international level serves as a powerful deterrent to policy change.
\end{abstract}

The adoption of progressive alcohol policy is at glacial speed despite the considerable evidence supporting its benefits. I've titled this paper "The Land of Insurmountable Opportunities” (from the Walt Kelly comic strip Pogo) because from my perspective the opportunities for change are substantial, but the barriers are all too often insurmountable. In recent decades we have seen substantial strides in the evidence for interventions, especially environmental approaches, but precious little improvement at the national level in alcohol policies, even while evidence of attributable harm grows (Room, 2013).

For example, here are just a few of the many U.S. researchbased documents that have focused on alcohol problems with recommendations for improvement in alcohol policies:

Surgeon General's Workshop on Drunk Driving (1988) Institute of Medicine's Report on Reducing Underage Drinking-A Collective Responsibility (2004)

Health and Human Services National Prevention Strategy (2011)

But these opportunities to improve public health through alcohol policies remain largely insurmountable, often due to barriers erected by vested interests. By way of example, when Dr. C. Everett Koop was U.S. Surgeon General, 99 members of the U.S. Senate called for him to convene experts to address drunk driving. Dr. Koop convened the workshop, gathering more than 100 researchers, advocates, victims, and others with expertise on the topic. Among the top ten recommendations:

o Increase price through taxation, with adjustments for inflation o Curb advertising and marketing practices that reach underage youth

o Strengthen laws limiting outlet density and days and hours of sale.

Today these policy prescriptions are well established, but they weren't in 1988. As the workshop was getting underway, the National Beer Wholesalers Association and the National Association of Broadcasters sued to halt the proceedings through a temporary restraining order. Dr. Koop prevailed and the workshop was held, but he permitted the industry to offer comments, many of which criticized the recommendations for containing a "neoprohibitionist agenda."

The workshop results helped create a paradigm shift in the way we thought about the problem, looking at alcoholimpaired driving as a function of the physical, social, cultural, and economic environments, rather than as moral weakness or addiction. But despite the Koop workshop results in response to the Senate request, there was no meaningful policy response.

Why the reluctance to take action? The U.S. Congress had taken action just two years before when University of Maryland basketball superstar Len Bias died from a cocaine overdose, just hours after he had signed a professional contract with the Boston Celtics. News media coverage was extensive, the nation was alarmed, and Congress took quick and decisive action, creating among other things a new federal agency, the Office for Substance Abuse Prevention (later the Center for Substance Abuse Prevention [CSAP]) and increasing funding for drug education in schools and communities, despite the lack of evidence on prevention effectiveness (Holder, 2009). 
Later, Congressional action was taken to confront the supposed advocacy of a CSAP grantee, the National Association for Public Health Policy, in conducting the Alcohol Policy 8 Conference, held in Washington, DC, in 1992, funded in part by a small conference grant. Some members of Congress, at the behest of alcohol industry executives, requested a Government Accountability Office (GAO) investigation on whether taxpayer funds had been used to support illegal lobbying, because the conference moderator at one point announced that free time on the agenda would allow attendees to visit members of Congress, if they wished. After its investigation, the GAO erroneously reported that some monies had been expended for the purpose of advocacy. Industry representatives trumpeted a victory. But actually the GAO never had spoken to the grantee. GAO later issued a one-page letter confirming that no grant funds had been used for advocacy.

Two years later, certain members of Congress took action to cut the CSAP budget substantially, based on an industry claim that the agency had overstepped its authority. How? The National Beer Wholesalers Association was troubled by a CSAP document reporting that environment approaches to prevention showed promise: "Laws that restrict availability and access as well as price increases have been used effectively as part of anti-abuse strategies." Industry representatives instead argued for more education of parents and youth, or "popular prevention." As Robin Room reminds us about prevention, "Popular approaches are ineffective; effective approaches are politically impossible” (Room, 2003).

In response, the House of Representatives cut the proposed CSAP budget by $73 \%$, whereupon Coors sent cases of beer to the subcommittee staff responsible for the action, as did the Beer Wholesalers, according to the Wall Street Journal. As reported, "The alcohol industry had good reason to be grateful. The bill would gut the Center for Substance Abuse Prevention, an agency the industry says promotes an antidrinking message threatening its bottom line" (Kuntz, 1995).

Today, the political climate for advancing alcohol policy remains poor. That's in part due to the view held by some that:

o Government overreaches when it attempts to change behaviors that might be considered a limit on individual freedom, no matter the improvement to health of the individual or to the public as a whole, whether it be sugar-sweetened beverages, junk food, or guns.

o Research that conflicts with ideology is dismissed and there are organized efforts to trivialize and marginalize scientific evidence on many public health issues, such as climate change.

o Market "freedom" allows corporations to promote the vectors of disease virtually unchecked by public health authorities, in the name of economic development and job creation.
Jahiel and Babor (2007) have referred to the alcohol problem as an "industrial epidemic" because alcoholic beverages are industrial products. The difference between natural epidemics and industrial epidemics is that the former are caused by natural agents and are driven by natural forces acting upon these agents, such as Plasmodium falciparum and Anopheles mosquitoes in the case of malaria. By contrast, industrial disease epidemics are driven at least in part by corporations and their allies that promote a dangerous product, such as tobacco or firearms. This understanding shifts the policy focus from the agent (alcohol) or the host (the problem drinker) to the disease vector (the alcohol industry and its associates), which in many ways is responsible for the exposure of vulnerable populations to the risks of alcohol. Policies to reduce the harm of industrial epidemics run the risk of being opposed by industrial corporations in a health versus profit trade-off. Others have pointed to the harm from transnational corporations' practices across various products (Moodie et al., 2013).

Recent research (Babor and Robaina, 2013) reveals an aggressive alcohol industry strategy to counter policies because they come into conflict with industry interests. Such efforts take the form of misrepresenting the public health view on alcohol policies, promoting prevention strategies known to be ineffective in lieu of more powerful approaches, and preparing draft alcohol strategies for governments that are willing to adopt them largely "as is."

Yet today action is being taken at state and local levels by a new generation of researchers and advocates. That's important in being able to address the changes in the industry in recent years, involving new players, especially retail businesses such as grocery and drug stores, that may not understand that alcohol is no ordinary commodity, and those who seek to roll back controls at the state and community level.

I fully endorse what the Alcohol Policy 16 conference cochair, Rebecca Ramirez, recommended on our first day of the conference. Her approach has been, she said, more of a "barge in" rather than the "lean in" strategy prescribed by a well-known female executive in a recently-popular book. That reminds me of what Surgeon General Koop recommended in addressing such intractable problems. "You don't necessarily have to have allies," he observed, “you can use co-belligerents!” (Koop, 1989).

\section{References}

Babor, T. F., and Robaina, K. (2013). Public health, academic medicine, and the alcohol industry's corporate social responsibility activities. American Journal of Public Health, 103(2), 206-214.

Holder, H. (2009). Prevention programs in the 21st century: What we do not discuss in public. Addiction, 105, 578-581.

Jahiel, R. I., and Babor, T. F. (2007). Industrial epidemics, public health advocacy and the alcohol industry: 
Lessons from other fields. Addiction, 102(9), 13351339.

Koop, C.E. (1989, May). Remarks at Press Conference. Findings of Surgeon General's workshop on drunk driving, Washington, D.C.

Kuntz, P. (1995, August 11). Alcoholic beverage industry lobbies for bill to gut substance abuse agency seen as a threat. The Wall Street Journal, p. A12.

Moodie, R., Stuckler, D., Monteiro, C., Sheron, N., Neal, B., Thamarangsi, T., . . . Casswell, S. (2013). Profits and pandemics: Prevention of harmful effects of tobacco, alcohol, and ultra-processed food and drink industries. The Lancet, 81(9867), 670-679.

Ramirez, R. (2013, April). Welcoming Remarks. Presented at Alcohol Policy 16: Building blocks for sound alcohol policies, Washington, D.C.

Room, R. (2003, March). Preventing alcohol problems: Popular approaches are ineffective; effective approaches are politically impossible. Paper presented at Alcohol Policy Conference 13: Building Bridges Between Research and Practice. Boston, MA.

Room, R. (2013). Alcohol as a public health risk: New evidence demands a stronger global response. The International Journal of Alcohol and Drug Research, 2(1), 7-9. 